\title{
Oncogene E1B
}

National Cancer Institute

\section{Source}

National Cancer Institute. Oncogene E1B. NCI Thesaurus. Code C45506.

Viral Oncogene E1B encodes 55-kDa E1B Protein, a regulator of early and late viral gene expression. E1B is implicated in selective nuclear export of viral late mRNAs and inhibition of export of cellular mRNAs. E1B counters host cell defenses mediated by p53. 